\title{
COMPETÊNCIAS SOCIOEMOCIONAIS: GÊNESE E INCORPORAÇÃO DE UMA NOÇÃO NA POLÍTICA CURRICULAR E NO ENSINO MÉDIO.
}

\section{SOCIO-EMOTIONAL COMPETENCES: GENESIS AND INCORPORATION OF A NOTION IN CURRICULUM POLICY AND HIGH SCHOOL.}

\author{
MAGALHÃES, Jonas Emanuel Pinto ${ }^{1}$
}

\section{RESUMO}

Este artigo procura mapear o percurso de incorporação da noção de competências socioemocionais nos discursos pedagógicos e nas políticas curriculares nacionais até a sua manifestação na reforma do ensino médio e na Base Nacional Comum Curricular. Analisa o papel desempenhado pelo Instituto Ayrton Senna na promoção e na disseminação das competências socioemocionais como inovação curricular consoante com a "Educação para o século XXI". Apresenta o projeto piloto "Solução Educacional" formulado e implementado por este Instituto em algumas escolas da rede estadual de ensino do Rio de Janeiro cujo foco volta-se para o desenvolvimento de competências não cognitivas. Por fim, discute, a partir dos relatórios produzidos pela OCDE, a influência deste organismo internacional na construção de uma agenda global que incorpore o desenvolvimento e a avaliação de competências socioemocionais como política educacional.

Palavras-chave: competências socioemocionais; políticas públicas, política educacional; currículo; ensino médio.

\section{ABSTRACT}

This article seeks to map the path of incorporating the notion of socio-emotional competences in pedagogical discourses and national curriculum policies up to its manifestation in high school reform and in the Brazilian common national curriculum base. It analyzes the role played by the Ayrton Senna Institute in promoting and disseminating socio-emotional skills as curriculum innovation in line with "Education for the 21st Century". It presents the pilot project "Educational Solution" formulated and implemented by that Institute in some schools in the Rio de Janeiro state public school system which focuses on the development of non-cognitive skills. Finally, based on the reports produced by the OECD, it discusses the influence of this international body in building a global agenda that incorporates the development and evaluation of socio-emotional competences as an educational policy.

KEYWORDS: socio-emotional skills; public policy, educational policy; curriculum; high school

1 Universidade Federal Fluminense - UFF. RJ, Brasil. Secretaria de Educação do Estado do Rio de Janeiro SEEDUC/RJ. Rio de Janeiro, RJ, Brasil. e-mail: jonasemanuel@ig.com.br 
DOI: $10.12957 / \mathrm{e}-\mathrm{mosaicos} .2021 .46754$

\section{INTRODUÇÃO}

A noção de competências penetra nos discursos e na política educacional da educação brasileira em meados dos anos 1990, especialmente, depois da promulgação da Lei de Diretrizes de Bases Nacionais da Educação (LDB) e da aprovação das Diretrizes Curriculares da Educação Profissional e das Diretrizes Curriculares Nacionais do Ensino Médio, respectivamente nos anos de 1996, 1998 e 1999.

No ensino médio, o parecer $n^{\circ} 15 / 98$ e a resolução $n^{\circ} 3 / 98$ do CNE/CEB foram os primeiros documentos pós-LDB a darem forma às diretrizes curriculares para a etapa final da educação básica. Nesta, a escola seria chamada a preparar os indivíduos para o mundo do trabalho, consolidando a aprendizagem de conteúdos, habilidades e competências de caráter geral requeridas por uma organização produtiva, que exige rápida assimilação das mudanças, criatividade, autonomia e capacidade de solucionar problemas. Nota-se a ênfase dada às competências gerais enquanto competências cognitivas básicas e complexas, relacionadas ao pensamento abstrato, a capacidade de deduzir, inferir, solucionar problemas e aprender. Tais competências dariam assim suporte para a formação profissional específica.

Seguindo essa linha, as Diretrizes Curriculares Nacionais para a Educação Profissional de Nível Técnico - parecer no 16/99 e resolução n 04/99 do CNE/CEB previram um perfil profissional configurado a partir de três tipos de competências: básicas - desenvolvidas na Educação Básica, profissionais gerais - próprias à área mais ampla de atuação profissional; e profissionais específicas, diretamente vinculadas a uma habilitação específica. Entendia por competência profissional "a capacidade de articular, mobilizar e colocar em ação valores, conhecimentos e habilidades necessários para o desempenho eficiente e eficaz de atividades requeridas pela natureza do trabalho." (BRASIL, 1999, p.2).

Já naquele momento, observam-se críticas à noção de competências que emerge desses documentos, especialmente por parte de pesquisadores vinculados ao campo trabalho e educação atentos ao deslocamento que tal noção provoca no conceito de qualificação.

Machado (1998), por exemplo, explica que a noção de competência não é em si uma novidade no campo da educação, mas é recuperado e ressignificado como constructo orientador do ensino médio a partir da nova forma como o mercado e a empresas têm gerido a força de trabalho através do que a sociologia do trabalho denominou "modelo de competências". Ocupando importante papel nos debates educacionais relacionados no âmbito dos organismos internacionais, a noção de competência aparece para a autora como um fetiche, mistificação que desconecta os sujeitos dos processos de trabalho e das condições e possibilidades sociais de permitem a sua efetivação construção. Subsumida à 
DOI: $10.12957 / \mathrm{e}-\mathrm{mosaicos} .2021 .46754$

lógica do capital, a noção de competência presta-se a definição das "condições subjetivas do desempenho dos sujeitos na realidade atual dos processos de trabalho e ao poder que possuem de negociar sua própria capacidade de trabalho" (MACHADO, 1998, p.22)

Endossando o entendimento da centralidade da noção de competências nas diretrizes curriculares do ensino médio e da educação profissional, Kuenzer (2003) vê, nas demandas postas pelo regime de acumulação flexível, novas exigências formativas sendo colocadas para o conjunto da classe trabalhadora em conjunto que estão ao mesmo tempo articuladas como novas formas de disciplinamento da força de trabalho. Apoiada numa nova matriz sociotécnica, o sistema produtivo sugere a necessidade de maior apropriação do conhecimento tácito dos trabalhadores, bem como uma nova articulação desses com o conhecimento explícito (teórico), o que necessariamente implicaria a formação de competências cognitivas complexas, adequadas para o enfretamento de situações de imprevisibilidade e de instabilidade dos sistemas de base microeletrônica. Para Kuenzer, entretanto, essas competências laborais só podem ser desenvolvidas satisfatoriamente em contexto reais de trabalho sendo, portanto, esta é uma competência das empresas e não do sistema educacional, a quem caberia "desenvolver as capacidades cognitivas, afetivas e psicomotoras relativas ao trabalho intelectual, sempre articulado, mas não reduzido, ao mundo do trabalho e das relações sociais" (KUENZER, 2002, p.10)

Ramos (2001), em estudo de referência, enxerga a noção de competências a partir de um movimento amplo e abrangente que abarca mudanças no mundo do trabalho e tentativa de correspondê-las no campo educacional por via de uma pedagogia das competências. De acordo com a autora, o fortalecimento da noção de competências tem um sentido técnico e político. Ao buscar uma aproximação entre a educação e as novas tendências produtivas, procura-se também orientar a passagem dos jovens ao trabalho em conformidade com o crescente processo de globalização e de crise do emprego. Isso explicaria a associação entre a noção de competências e as noções de empregabilidade e laboralidade. A centralidade adquirida pela noção de competências no mundo do trabalho e a consequente psicologização das questões sociais terão desdobramentos não desprezíveis no campo da educação.

No que se refere mais especificamente à educação profissional, Ramos (2002) observa incoerências internas nos documentos de referência da educação profissional, que anunciam as competências como princípio formativo adequado à flexibilidade e à complexidade atual dos processos de trabalho, mas manifestam-se como prescrições de perfis e atividades profissionais rígidos e estáveis, tais como o padrão taylorista-fordista. Além disso, apropriam-se do referencial piagetiano através de uma abordagem neopragmatista que, convergindo para um subjetivismo radical, acaba recaindo numa perspectiva funcionalista e condutivista da formação. Para além de tais incoerências identificadas nos documentos, a autora vê como problemáticas "as referências éticopolíticas, epistemológicas e metodológicas que embasam a concepção de qualificação e 
DOI: $10.12957 / \mathrm{e}-\mathrm{mosaicos} .2021 .46754$

competência, de conhecimento e de aprendizagem neles veiculadas" (RAMOS, 2002, p.419)

As diretrizes do ensino médio e da educação profissional de nível técnico refletem, em grande medida, o contexto da reforma educacional que sob a égide do decreto 2.208/97 regulamentou a educação profissional de nível médio. Apenas alguns anos após a revogação do decreto em 2004, o Conselho Nacional de Educação pôs em pauta a formulação de novas diretrizes para o ensino médio e para educação profissional de nível técnico. Esse processo, iniciado nos anos 2010, redimensionou, de modo diferenciado, a noção de competências na estruturação curricular desses dois níveis de ensino.

Enquanto nas novas diretrizes curriculares do ensino médio, a noção de competências perde força em virtude de uma reorientação curricular centrada na articulação das dimensões do trabalho, ciência, cultura e tecnologia e no trabalho como princípio educativo, nas novas diretrizes para a educação profissional de nível técnico, o perfil profissional passa a ser buscado pela identificação de conhecimentos, saberes e competências profissionais e pessoais requeridas pela natureza do trabalho. Não se perde aqui a noção de competências básicas, profissionais gerais e profissionais específicas, nos termos propostos pelas antigas diretrizes. Contudo, há um claro alargamento do conceito de competências básicas como competências pessoais. ${ }^{2}$

Assim, as competências básicas, que, nas diretrizes curriculares do ensino médio, podiam ser identificadas como competências cognitivas se traduzem nas novas diretrizes da educação profissional de nível técnico como competências pessoais, o que no nosso entender, amplia o seu espectro para a dimensão socioemocional. Interessante notar que embora as novas DCNs da educação profissional de nível técnico proponham que a identificação do perfil profissional seja buscada pela definição dos conhecimentos, dos saberes e das competências profissionais e pessoais requeridas pela natureza do trabalho, esse segundo termo (pessoais) é omitido no artigo $5^{\circ}$, que se refere à finalidade da educação profissional técnica de nível médio, o que reforça o entendimento de que caberia à educação básica desenvolver as competências pessoais.

Desse modo, observamos como um elemento novo nas atuais DCNs da Educação Profissional Técnica de Nível Médio (resolução 06/2012 do CNE/CEB) e do Ensino Médio (resolução 03/2018 do CNE/CEB) uma maior amplitude conferida à noção de competências, no primeiro caso, tratadas como competências profissionais e pessoais e no segundo, assumindo-se como parte da formação integral dos estudantes o desenvolvimento de "habilidades socioemocionais".

2 Cabe registrar que o parecer inicial proposto pelo relator do CNE, Francisco Cordão, propunha como núcleo da proposta o curricular o conceito de CHAVE, sigla que sintetizaria os componentes da competência. Acrescentando "valores e emoções" aos componentes já introduzidos pelo parecer 16/99 (conhecimentos, habilidades e atitudes), a proposta curricular centrada no conceito de CHAVE remeteria então às dimensões dos quatros saberes (conhecer, fazer, ser, conviver) propostos para o milênio no relatório da Unesco (1998). 
DOI: $10.12957 / \mathrm{e}-\mathrm{mosaicos} .2021 .46754$

Corroborando com essa perspectiva de conferir maior extensão à noção de competências, observamos desde 2011, tendências que buscam revitalizar a noção de competências e os discursos que as justificam como integrantes do currículo. A partir de uma agenda protagonizada pela Organização para a Cooperação e Desenvolvimento Econômico (OCDE), essa revitalização teve como principal protagonista no Brasil o Instituto Ayrton Senna (IAS) e assenta-se no deslocamento de ênfase das competências cognitivas para as competências socioemocionais. Num primeiro momento, esse deslocamento manifestou-se no plano da construção de um discurso, buscando a construção de um consenso conceitual, pedagógico e terminológico ${ }^{3}$, mas ganhou maior materialidade através das parcerias público-privadas estabelecidas pelo IAS, das quais se destaca a que resultou na reformulação curricular do ensino médio no Estado do Rio de Janeiro. Posteriormente, observa-se a incorporação dessa agenda em documentos de políticas curriculares e educacionais nacionais, incluindo a Base Nacional Comum Curricular (BNCC).

\section{O Seminário Educação para O século 21: a "descoberta" das competÊnCias SOCIOEMOCIONAIS.}

O seminário Educação para o século 21, promovido pelo IAS em parceria com a Secretaria de Assuntos Estratégicos da Presidência da República (SAE) e com a Organização das Nações Unidas para a Educação, a Ciência e a Cultura (UNESCO), inaugura uma nova fase de incorporação da noção de competências ao cenário educacional brasileiro. As competências socioemocionais despontam neste cenário como uma inovação curricular, cuja proeminência é justificada por sua correlação com o sucesso escolar - o que seria atestado por recentes descobertas no campo da investigação dos processos de ensino-aprendizagem conduzidos por estudos internacionais. Conforme destacam os organizadores do seminário na página eletrônica do evento:

Por meio desses estudos, sabemos hoje que o êxito na aprendizagem não acontece apenas pelos investimentos feitos no campo exclusivo da cognição - onde se concentram a maior parte dos esforços públicos e privados em educação -, mas são altamente impactados pelo

3 Pela multirrencialidade do objeto em questão, tem-se utilizado como termos sinônimos habilidades nãocognitivas (soft skills), habilidades socioemocionais, competências não cognitivas e competências socioemocionais, inteligência emocional, inteligência social etc. A diversidade terminológica reflete a abordagens por diferentes campos do saber: economia, sociologia, psicologia, neurociência, educação. Não aprofundaremos as razões e implicações dessas distinções, mas trazemos esse dado para registrar que no Brasil tem se construído um consenso, pelo menos no campo da educação, em torno do termo competências socioemocionais, o que está relacionado com os agentes que vêm buscando ampliar o seu espaço na definição das políticas curriculares. 
DOI: $10.12957 /$ e-mosaicos.2021.46754

desenvolvimento de outros atributos pessoais, que praticamente não são objeto das políticas educacionais: persistência e disciplina, capacidade de atenção e concentração, capacidade de adiar recompensas, autoestima, sociabilidade, dentre outros, denominados de diversas formas, como competências comportamentais, relacionais, emocionais, atitudinais, socioafetivas, não cognitivas etc. (Instituto Ayrton Senna, 2011, s/p.)

O seminário realizado no dia 25 de outubro de 2011 contou com a presença de representantes do MEC, da União Nacional dos Dirigentes Municipais de Educação (Undime) e o Conselho Nacional de Secretários de Educação (Consed), além de ONGs e convidados especiais. Os palestrantes nacionais e internacionais discutiram sobre três temas principais: inovação, valores e competências não cognitivas. Coube a James Heckman, economista americano, ganhador do prêmio Nobel de economia 2000, a apresentação do painel "Competências não cognitivas: sinergia e impacto sobre as cognitivas".

Embora o evento, por sua natureza, não tenha produzido nenhuma síntese ou documento, registra-se através de sua página eletrônica do evento a concordância entre os palestrantes sobre a necessidade de inclusão das competências não cognitivas no currículo escolar. Posteriormente, matérias do jornal Folha de São Paulo repercutiram a discussão sobre as competências socioemocionais promovidas no seminário.

No ano seguinte ao da realização do seminário, a Secretaria de Educação do Estado do Rio de Janeiro (SEEDUC-RJ) e o IAS firmam uma parceria para elaboração de uma proposta curricular para Escolas de Ensino Médio em Tempo Integral. Passamos a descrever e analisar alguns dos aspectos e particularidades do modelo desenvolvido inicialmente no Colégio Estadual Chico Anysio (CECA).

\section{"SOluÇÃo EduCACIONAL": O MOdELO CURRICULAR DE REFERÊNCIA PARA O ENSINO}

\section{EM TEMPO INTEgRAL NO Estado DE RIO DE JANEIRO.}

O IAS se apresenta como uma organização social sem fins lucrativos que desenvolve tecnologias, programas de formação e projetos educacionais voltados para melhoria da qualidade na educação, atuando em parceria com as redes públicas de ensino. Conforme informações do site eletrônico do Instituto, essas parcerias se estendem hoje para 17 estados e mais de 660 municípios.

Na rede estadual de ensino do Rio de Janeiro, a parceria, iniciada em 2012, é formaliza em 2013 através do convênio SEEDUC 10/2013. Resulta dessa parceria uma pesquisa realizada com alunos para avaliação de competências socioemocionais e a implementação de um modelo curricular voltada para a integração curricular e para o 
DOI: $10.12957 / \mathrm{e}-\mathrm{mosaicos} .2021 .46754$

desenvolvimento de competências cognitivas e não cognitivas. Esse modelo, denominado "solução educacional", passa a ser referência para a reestruturação do ensino médio no estado, influenciando o programa de implementação do ensino médio integral e a normatização das novas diretrizes curriculares pelo Conselho Estadual de Educação (CEE/RJ).

O modelo curricular Solução Educacional surge em resposta à expansão do ensino médio integral na rede estadual do Rio de Janeiro. Por outra via, essa expansão já vinha sendo esboçada por meio do programa Dupla Escola ${ }^{4}$ e da adesão do governo do estado ao programa Ensino Médio Inovador (PROEMI) ${ }^{5}$. A proposta curricular da solução educacional insere-se no contexto de reformulação da política educacional do ensino médio no estado. Conforme exposto no site eletrônico da SEEDUC/RJ:

O projeto não se resume à implementação de um novo currículo. Trata-se uma iniciativa de educação integral que altera os paradigmas das políticas educacionais do ensino médio do Rio de Janeiro, introduzindo novos modelos e processos de gestão, formação, acompanhamento e avaliação, que viabilizam e se ancoram em uma proposta curricular inovadora. (SEEDUC, 2015, s/p)

$\mathrm{Na}$ apresentação dos conceitos que embasam a proposta curricular "Solução Educacional", o IAS faz críticas ao currículo do ensino médio no qual predomina o que considera "uma estrutura curricular excessiva e fragmentada que levou a educação juvenil a divorciar-se do mundo do trabalho e das questões e aspirações dos jovens." (INSTITUTO AYRTON SENNA, 2012, p.8). Sua proposta de educação plena, ou integral, consistiria em dar um tratamento integrador ao currículo escolar, desenvolvendo competências cognitivas (relacionados ao conhecer) e não cognitivas (relacionados ao ser, conviver e fazer), estimulando o protagonismo juvenil e a aprendizagem colaborativa e significativa. A matriz de competências para o século 21 orienta a proposta curricular. Composta por dez macrocompetências, essa matriz se relaciona às dimensões do conhecer, do fazer, do ser e do conviver, integrando assim competências cognitivas e não cognitivas, conforme o esquema proposto no documento e reproduzido abaixo:

40 programa dupla-escola existe desde 2008 e sustenta-se através de parcerias público-privadas com empresas, ONGs, consulados e instituições de ensino. Como modelo de escola em tempo integral oferece formação profissional em nível médio na modalidade integrada. O Colégio Estadual José Leite Lopes, conhecido como Nave (Núcleo Avançado em Educação) e Colégio Comendador Valentim dos Santos Diniz, também conhecido como Nata (Núcleo Avançado em Tecnologia de Alimentos) são os exemplos mais emblemáticos dessas parcerias, respectivamente, estabelecidas com a empresa Oi telefônica e com o Grupo Pão de Açúcar.

5 O PROEMI é um programa do governo federal, instituído pela Portaria no 971, de 9 de outubro de 2009, que visa apoiar e fortalecer o desenvolvimento de propostas curriculares inovadoras nas escolas de Ensino Médio. Atualmente, é desenvolvido em 53 escolas da rede estadual. 
Fig.1: Matriz de Competências.

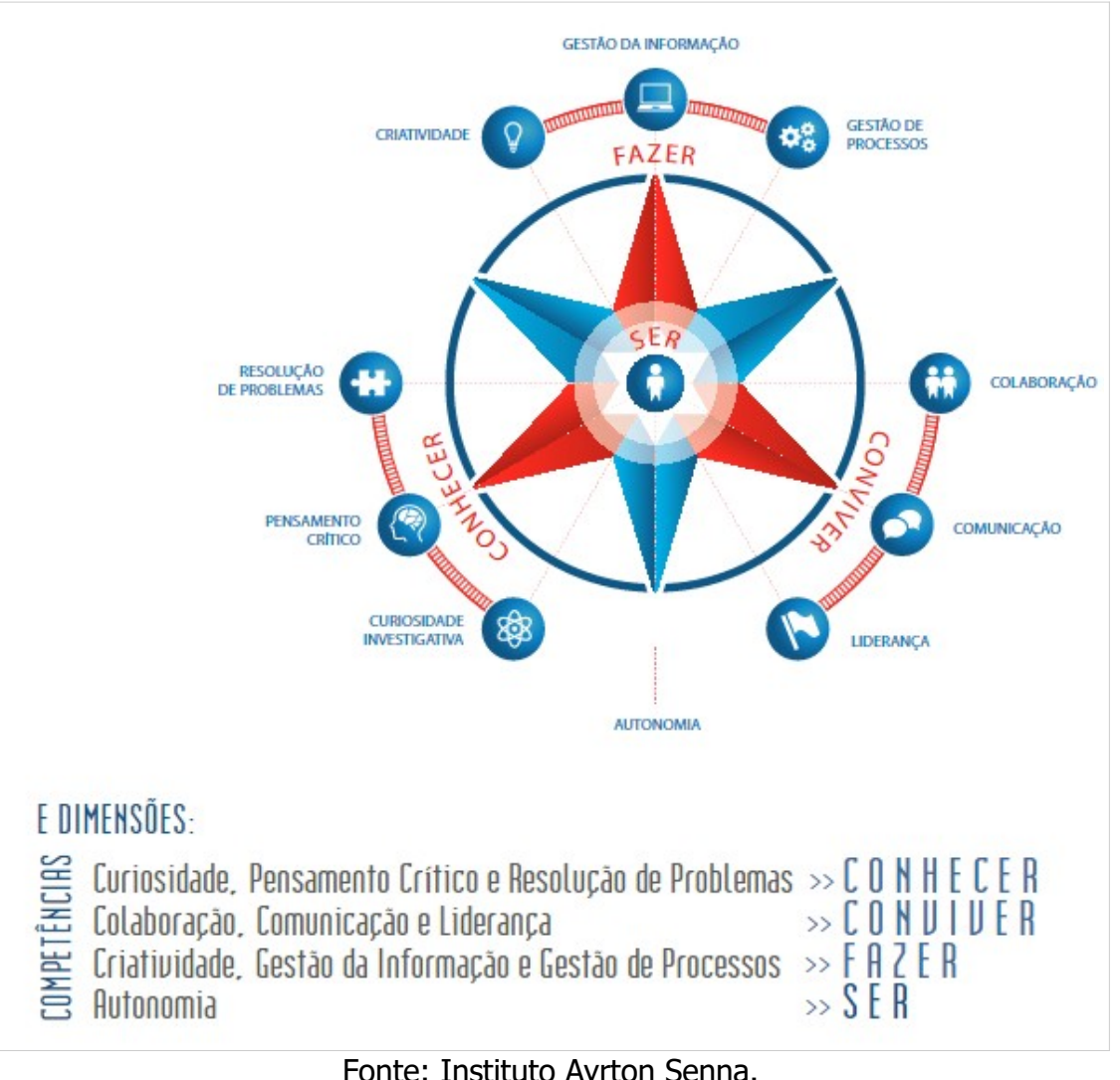

Fonte: Instituto Ayrton Senna.

A proposta curricular Solução Educacional do Ensino Médio foi elaborada no ano de 2012 com vistas a sua implementação como projeto piloto no CECA no ano de 2013 e posterior expansão para outras escolas da rede estadual de ensino.

A pavimentação do caminho para a implementação das mudanças curriculares nas escolas da rede estadual foi concluída em dezembro de 2012 com a publicação das Resoluções SEEDUC/RJ n 4842/2012 e n 4843/2012. A primeira fixou diretrizes para a implantação das matrizes curriculares para o ensino médio integrado à educação profissional e para ensino médio experimental (Solução Educacional) e a segunda fixou diretrizes para os demais níveis e modalidades de ensino.

Pelo texto da Resolução $n^{\circ} 4842 / 2012$, o ensino médio experimental deveria dedicar a parte específica para o "desenvolvimento de competências para uma cultura de trabalho e estruturada através de disciplinas, projetos e/ou módulos", podendo organizar essa parte do currículo em quatro dimensões: trabalho, convívio, aprendizagem e formação para a autonomia. Já a Resolução n 4843/2012 previa para as escolas 
DOI: $10.12957 / \mathrm{e}-m o s a i c o s .2021 .46754$

participantes do PROEMI tempos dedicados a projetos de intervenção e iniciação científica, letramento em língua portuguesa e matemática e laboratórios de culturas e arte, cultura e uso de mídias e cultura corporal. Com a extensão da carga horária, esses dois modelos passaram a ser denominados Ensino Médio Integral de Referência (matriz da Solução Educacional) e Ensino Médio Integral Nova Geração (Escolas de PROEMI com matriz curricular adaptada).

Chama a atenção nas matrizes curriculares para esses dois modelos a inserção dos componentes curriculares como projetos de vida e de intervenção e pesquisa como núcleo articulador das dimensões do trabalho, da ciência da cultura e da tecnologia. Nos documentos da Solução Educacional, não há uma discussão teórico-filosófica aprofundada sobre o significado dessas dimensões. Nota-se uma apropriação indébita do pensamento crítico cujo cerne é concepção de trabalho como princípio educativo e de ciência, cultura e tecnologia como eixos de um projeto de formação integral e integrada. Neste caso, o que se observa é um desvio do pensamento crítico para a ênfase no individualismo. $\mathrm{Na}$ realidade, os componentes de projeto se prestam, conforme anunciado pelo Instituto Ayrton Senna, ao desenvolvimento das competências não cognitivas. De fato, parece ter sido este um arranjo curricular estratégico necessário para revitalizar a noção de competências no currículo que havia perdido seu vigor com as novas diretrizes curriculares do ensino médio.

Chaves, Motta e Gawryszewski (2020), analisando o programa Solução Educacional, concluem que ele se apresenta como uma tecnologia social de caráter técnico e sem mediações ideológicas. Desse modo:

(...) operando no nível concreto-real, tenta-se incorporar essa ideia, de modo a aceitar sem muita reflexão a suposta necessidade de aprender competências socioemocionais na escola, como se fosse um caminho destituído de ideologias, constituindo-se apenas numa jornada neutra, apolítica e somente técnica (CHAVES, MOTTA e GAWRYSZEWSKI, 2020, p.14)

A despeito das contradições e condições infraestruturais apontadas pelos autores como limites para a plena implementação dessa proposta, entendemos que, de fato, a rede estadual de ensino do Rio de Janeiro parece ter servido como balão de ensaio e como vitrine para propostas curriculares, baseada em competências socioemocionais, tais como o programa Solução Educacional. Como veremos, após 2013, o IAS, através de um forte intercâmbio e articulação com agentes governamentais, manteve-se empenhado na consolidação da agenda e fomento da implementação de políticas públicas, voltadas para o desenvolvimento de competências socioemocionais na escola. 
DOI: $10.12957 / \mathrm{e}-m o s a i c o s .2021 .46754$

\section{O Fórum Internacional de Políticas Públicas "Educar para as Competências do SÉCULO 21": ASSUMINDO A PAUTA INTERNACIONAL.}

O Fórum Internacional de Políticas Públicas "Educar para as Competências do Século 21", realizado nos dias 24 e 25 de março de 2014, demarca fortemente o impulso dado à temática das competências socioemocionais no Brasil e a incorporação do seu discurso apologético por agentes do Estado. O Fórum, organizado pelo IAS em conjunto com a OCDE e o MEC, contou com a presença de 14 ministros e altos representantes de países membros da OCDE, pesquisadores internacionais, dentre eles, James Heckam, principal palestrante do seminário sobre a mesma temática organizado em 2011 pelo Instituto, além de gestores da educação no Brasil e de outros países. Os três fóruns (de ministros, de gestores e de pesquisadores) focaram o debate em quatro grandes objetivos:

Compreender quais competências são importantes; compreender os mecanismos de formação de competências e desenvolver melhores práticas para promovê-las, medir competências socioemocionais e melhorar políticas públicas e contextos de aprendizagem; desenvolver estratégias para garantir uma abordagem plena e coerente para o desenvolvimento de competências." (OCDE, Sumário: Fórum de Ministros 2014, s/p)

Como síntese do fórum dos Ministros, realizado em sessão fechada, a OCDE produziu um sumário com algumas conclusões e encaminhamentos acordados entre os representantes políticos dos países presentes. Dentre os consensos estabelecidos, os representantes reconhecem as competências socioemocionais como um importante instrumento para melhoria de índices econômicos, sociais e educacionais e com possíveis impactos sobre as desigualdades sociais. Convencidos de que as competências socioemocionais são maleáveis, também concordam que o foco das políticas não deve se restringir à primeira infância. Houve um consenso também de que as competências (cognitivas e socioemocionais) podem ser mensuradas de forma significativa, ainda que se devam considerar os incentivos e os esforços associados ao desempenho de tarefas envolvidas nessa medição. Ressaltam como competências cognitivas importantes o letramento e o numeramento, assim como as competências socioemocionais relacionadas ao trabalho em equipe, perseverança, resiliência e comunicação. Também consideram importante considerar a capacidade dos professores em promover as competências socioemocionais.

Os participantes defenderam ainda o diálogo entre os formuladores de políticas públicas e a comunidade científica com vistas à elaboração de diretrizes com base em novas evidências científicas, especialmente sobre duas questões: definição de 
DOI: $10.12957 / \mathrm{e}-\mathrm{mosaicos} .2021 .46754$

competências socioemocionais que incidem diretamente sobre resultados específicos e os mecanismos que possibilitariam ampliá-las. O sumário destaca que o Brasil esteve entre os países que defenderam o levantamento de dados em larga escala e encerra-se com o compromisso da OCDE de:

(...) continuará a fazer esforços para ajudar a fortalecer a base de dados em um estudo longitudinal sobre a formação de competências desde a infância até a adolescência em diferentes países. Nós também vamos continuar buscando contribuições de grandes cientistas, como o professor Heckman, para que os países compartilhem o conhecimento para melhorar as decisões de políticas públicas. Por último, mas não menos importante, nós vamos continuar a trabalhar junto aos países da OCDE e parceiros para aprender com suas experiências e para promover as competências socioemocionais entre os diferentes atores. Estamos certos de que esses esforços serão complementares aos investimentos consideráveis que já são feitos (ou planejados) pelo Ministério da Educação do Brasil e pelo Instituto Ayrton Senna. (OCDE, Sumário: Fórum de Ministros, 2014, p.4)

A repercussão desse Fórum pode ser medida não só pela maior ênfase dada às competências socioemocionais nos discursos de gestores educacionais, agentes do estado e de alguns representantes do $\mathrm{CNE}_{\text {, }}$ mas também, e, principalmente, pelos desdobramentos concretos que se seguiram a partir de iniciativas Coordenação de Aperfeiçoamento de Pessoal de Nível Superior (CAPES), do CNE e do IAS.

\section{As COMPETÊNCIAS SOCIOEMOCIONAIS EM PAUTA: MANIFESTAÇõES NA POLÍtICA EDUCACIONAL E NOS TEXTOS OFICIAIS.}

Passados três meses do Fórum, a CAPES, em parceria com o IAS, criava o Programa de Apoio à Formação de Profissionais no Campo das Competências Socioemocionais. Através do edital $n^{\circ} 44 / 2014$, o programa propunha o financiamento de 10 projetos de pesquisa-ação e de pesquisa participativa voltadas para o desenvolvimento de competências socioemocionais em todos os níveis de ensino e pesquisa. Dentre os objetivos específicos se expressa o interesse pela formação de professores para o trabalho com as competências socioemocionais, fortalecimento dessa linha de pesquisa no âmbito da pós-graduação e do diálogo entre a produção científica, as políticas públicas e os atores envolvidos diretamente no processo educacional.

Com a chamada reforma de ensino médio (resultado da transformação da medida provisória em lei) e, pouco depois, com a divulgação da versão final da BNCC do ensino médio, as competências socioemocionais ganharam novo espaço na proposta curricular 
DOI: $10.12957 /$ e-mosaicos.2021.46754

desta etapa do ensino. Assim a lei 13.415 de 2017, ao tratar da BNCC do Ensino Médio, modifica o artigo 35-A da LDB e estabelece que:

Os currículos do ensino médio deverão considerar a formação integral do aluno, de maneira a adotar um trabalho voltado para a construção de seu projeto de vida e para sua formação nos aspectos físicos, cognitivos e socioemocionais (BRASIL, 2018, s/p)

Aprovada no ano seguinte à reforma do ensino médio, a versão final da BNCC, prevê o desenvolvimento de dez competências gerais a serem perseguidas durante esta etapa de ensino. Em consonância com o artigo acima citado, as três últimas competências definidas no documento explicitam de forma bastante evidente a dimensão socioemocional incorporada à noção de competências, tais quais citamos literalmente abaixo:

8 - Conhecer-se, apreciar-se e cuidar de sua saúde física e emocional, compreendendo-se na diversidade humana e reconhecendo suas emoções e as dos outros, com autocrítica e capacidade para lidar com elas. 9. Exercitar a empatia, o diálogo, a resolução de conflitos e a cooperação, fazendo-se respeitar e promovendo o respeito ao outro e aos direitos humanos, com acolhimento e valorização da diversidade de indivíduos e de grupos sociais, seus saberes, identidades, culturas e potencialidades, sem preconceitos de qualquer natureza. 10. Agir pessoal e coletivamente com autonomia, responsabilidade, flexibilidade, resiliência e determinação, tomando decisões com base em princípios éticos, democráticos, inclusivos, sustentáveis e solidários. (BRASIL, 2018, p.10)

É válido destacar que a defesa em torno da aprovação da BNCC teve como importante aliado o "Movimento Pela Base", constituído por intelectuais que apoiaram a reforma do ensino médio, a União dos Dirigentes Municipais de Educação, Conselho Nacional de Secretários de Educação e o movimento Todos Pela Educação (TPE), este último comparece como uma importante articulação de representantes da burguesia brasileira que visam a influir na política educacional, assumindo pautas consoantes com a agenda neoliberal.

Conforme explicam Leher e Evangelista (2012), o TPE é resultado de uma liderada pelo setor financeiro em articulação com o setor siderúrgico de commodities. De fato, o TPE tem hoje como principais mantenedores fundações ligadas aos bancos Itaú, Bradesco, Unibanco e Santander. Os autores lembram ainda que, embora apresente-se como uma 
DOI: $10.12957 / \mathrm{e}-\mathrm{mosaicos} .2021 .46754$

iniciativa de classe o TPE, ou seja, desvinculada do Estado e do governo, precisa operar por meio destes para dar concretude aos seus objetivos. Desse modo, o TPE vem se articulando desde meados dos anos 2000 com secretarias e gestores da educação pública e atuando por meio de suas fundações e organizações sociais na implementação de projetos, venda de pacotes de matérias didáticas e consultorias no campo da gestão e do currículo.

Não por acaso, uma das organizações sociais ligada ao TPE com maior atuação na consolidação de parcerias com secretarias de educação nos estados e municípios tem sido justamente o IAS. Sua participação e seu protagonismo na elaboração de propostas curriculares e de avaliação para o desenvolvimento de competências sociemocionais revela a influência desses novos atores sociais na definição dos rumos da política educacional.

De outro modo, o recente interesse de organizações sociais, gestores de sistemas de educação e formuladores de políticas curriculares nas competências socioemocionais, em contraste com o reduzido número de pesquisas sobre esse tema em âmbito nacional, especialmente no campo da educação, nos leva a buscar explicações para esse fenômeno na subordinação e adequação das políticas públicas às orientações emanadas por organismos internacionais. No caso específico das competências socioemocionais, é possível observar o papel relevante que a OCDE vem ocupando na inclusão e consolidação dessa agenda como política pública a ser incorporada pelos países membros e associados, caso específico do Brasil.

\section{AS COMPETÊNCIAS SOCIOEMOCIONAIS NA AGENDA INTERNACIONAL DA EDUCAÇÃO: O PAPEL DA OCDE E SUA INFLUÊNCIA NAS POLÍTICAS DE AVALIAÇÃO E CURRÍCULO.}

As diferentes terminologias para designar as competências socioemocionais encontradas nos textos oficiais não parecem resultar de divergências em relação ao seu real conteúdo. Os propósitos mais gerais e os argumentos político-pedagógicos utilizado nos discursos de seus principais agentes buscam respaldar-se de alguma forma em evidências científicas - ainda pouco consistentes no que diz respeito ao papel e ao potencial da escola na promoção das competências socioemocionais -, mas convergem para concepções que fundamentam diretrizes e orientações da OCDE dirigidas a países em desenvolvimento. Nas políticas de avaliação educacional em larga escala, o foco nas competências de letramento e de numeramento somam-se às mais recentes indicações da OCDE para incorporação no currículo de competências socioemocionais e da viabilidade da construção de instrumentos para mensuração dessas competências.

Desde a criação do PISA, o programa internacional de estudantes, em 1997, a OCDE vem produzindo estudos para subsidiar a formulação e a aplicação do exame. Naquele mesmo ano, lançou o Projeto DeSeCo (sigla em inglês para definição e seleção de 
DOI: $10.12957 / \mathrm{e}-\mathrm{mosaicos} .2021 .46754$

competências: fundamentos teóricos e conceptuais) com o objetivo de construir um quadro conceitual para identificação das competências-chaves, fortalecer as avaliações internacionais e ajudar a definir metas globais para os sistemas educativos. Em 2005, a OCDE divulgou, como resultado deste projeto, o documento "The definition and selection of key competencies", um sumário executivo com indicações das competências-chaves necessárias aos indivíduos para o enfretamento dos "desafios do mundo contemporâneo". Já naquele momento, sustentava que uma competência não se restringe ao domínio de conhecimentos e habilidades, mas "(...) envolve a capacidade de satisfazer demandas complexas, recorrendo e mobilizando recursos psicossociais (incluindo habilidades e atitudes) em um contexto particular." (OCDE, 2005, p. 4).

O sumário executivo define três grandes categorias, inter-relacionadas, mas foco específico, que formariam a base para o mapeamento e a identificação das competênciaschaves:

1 Competência para o uso interativo de ferramentas, o que envolve a capacidade de usar símbolos, linguagem, textos, conhecimento, informação e tecnologia de forma interativa

2 Competência para interagir em grupos heterogêneos, o que envolve a capacidade de relacionar-se bem com os outros, cooperar e trabalhar em equipe e gerir e resolver conflitos.

3 Competência para atuar com autonomia, o que envolve a capacidade de agir de acordo com o contexto mais amplo em que se está inserido, construir e conduzir seus planos de vida e projetos pessoais e fazer valer seus direitos, interesses, limites e necessidades.

Entretanto, apesar da definição categorial das competências, o sumário admite que elas se combinem, em contextos diferenciados, não sendo factível pensar na mobilização de uma única competência em situações reais. Essa ressalva talvez justifique a não mensuração direta, pelo menos naquele momento, de competências de caráter mais pessoal (socioemocionais).

De fato, as avaliações do PISA têm, desde a sua primeira edição em 2000, dirigido o seu foco para as competências ligadas às áreas da linguagem, matemática e ciências, mais diretamente relacionadas, portanto, à primeira categoria de competências-chave. 0 impacto de variáveis socioeconômicas, do ambiente familiar e escolar e de aspectos subjetivos e emocionais dos alunos sobre o desempenho no exame vem sendo avaliado a partir da aplicação de questionários aos alunos, diretores de escolas e pais de alunos (indicadores contextuais). Os resultados do PISA 2012 indicaram uma correlação significativa entre o desempenho em matemática e atitudes em relação à escola, motivação e engajamento com a aprendizagem (VIEIRA, 2015 apua OCDE, 2014) 
DOI: $10.12957 / \mathrm{e}-\mathrm{mosaicos} .2021 .46754$

De acordo com o autor citado acima, para avaliação do PISA 2015 foram incluídas no questionário contextual do estudante duas novas questões sobre perseverança e abertura à resolução de problemas. Na edição do PISA 2015, abordou-se o letramento científico com foco na resolução de problemas, mas foram acrescentadas duas novas áreas de conhecimento: Competência Financeira e Resolução Colaborativa de Problemas. Esta foi a primeira edição do exame totalmente realizada por meio virtual, o que provavelmente, possibilitou o trabalho conjunto de alunos para resolução de problemas.

Evidencia-se com essas mudanças no PISA 2015, a tentativa da OCDE de operacionalizar formas de avaliação que contemplem, de forma mais abrangente e específica, as competências-chaves delineadas. Neste caso, a competência para usar ferramentas da tecnologia de forma interativa e competência que envolve a cooperação e o trabalho de equipe poderia ser avaliada de forma mais objetiva do que com o uso de questionários. Sinaliza-se, ainda, a intenção da OCDE de elaborar instrumentos que permitam mensurar, de forma mais independente e objetiva, as competências socioemocionais.

Nota-se aqui uma reconfiguração no padrão de tratamento dado às competências socioemocionais pela OCDE. Se antes essas competências apareciam diluídas na discussão mais geral sobre as competências como um componente identificável, mas dificilmente mensurável por sua articulação dinâmica com as competências cognitivas, hoje se admite não só a possibilidade de avaliação objetiva em por instrumentos psicométricos, como se distingue, a partir de constructos teóricos, atributos específicos e próprios desse tipo de competência. A OCDE, apoiado em alguns estudos realizados por economistas e psicólogos, vem destacando cada vez mais as competências socioemocionais em suas ações, políticas e discursos.

O relatório "Competências para o Progresso Social", que serviu de referência para as discussões do Fórum Internacional de Políticas Públicas: Educar para as Competências do Século 21" encaminha a discussão nesse sentido, estabelecendo uma relação direta entre as necessidades dos empregadores e as demandas que a escola deveria dar conta:

Tem sido cada vez mais difícil passar diretamente da escola para o trabalho. Por outro lado, empregadores também estão tendo muitas dificuldades em encontrar empregados com as competências necessárias (....) Esses desafios só podem ser alcançados por indivíduos com um conjunto abrangente de competências cognitivas e socioemocionais. Os formuladores de políticas públicas precisam considerar um amplo leque de habilidades, no qual as competências socioemocionais são tão importantes quanto as competências cognitivas. (OCDE, 2014, p.4) 
DOI: $10.12957 / \mathrm{e}-\mathrm{mosaicos} .2021 .46754$

O relatório traz ainda alguns resultados de pesquisas que apontam para relação entre competências socioemocionais e melhorias nos índices sociais. As competências socioemocionais seriam então um importante instrumento a ser considerado nas políticas públicas como formar de conter índices de violência, depressão, bullying, obesidade, gravidez precoce e diminuição das desigualdades sociais. As competências socioemocionais teriam impactos para o progresso social, econômico e individual. Se expressa um entendimento meritocrático, competitivo e seletivo da sociabilidade contemporânea, na qual teriam vantagens indivíduos com as competências socioemocionais mais desenvolvidas e ajustadas a esta realidade:

As evidências empíricas e o senso comum nos dizem que competências socioemocionais permitem que as pessoas lidem melhor com os desafios cotidianos. Indivíduos que persistem e se esforçam mais têm maior tendência ao sucesso em um mercado de trabalho altamente dinâmico e orientado por habilidades. Aqueles que são mais capazes de controlar seus impulsos tendem a seguir padrões de vida mais saudáveis e permanecer em boa forma. Indivíduos que são capazes de lidar com suas emoções e conseguem se adaptar a mudanças tendem a lidar melhor com os problemas da vida, como perda de emprego, desestruturação familiar ou envolvimento com crime. (OCDE, 2014, p.1)

O sumário síntese do Fórum de Ministros reafirma o consenso em torno das competências socioemocionais enquanto ferramenta para diminuição da desigualdade social, econômica e social e o compromisso dos representantes dos países presentes e da OCDE com o investimento nas competências socioemocionais nos diversos níveis de ensino e com a continuidade e aprofundamento do diálogo entre a comunidade científica e os formuladores de políticas públicas. Essas, também, são conclusões descritas no relatório de pesquisa do Centro para Pesquisa e Inovação Educacional (CERI, sigla em inglês) da OCDE, publicado em 2015, no qual se afirma que competências socioemocionais como "perseverança, sociabilidade e autoestima mostraram-se capazes de influenciar várias dimensões da vida social futura, incluindo saúde melhor, mais bem-estar subjetivo e menor possibilidade de envolvimento com problemas de conduta." (OCDE, 2015, p.3). Seguindo uma tendência observada por Evangelista e Shiroma (2006), os organismos internacionais vem, desde 0 final da década de noventa, investindo numa linguagem menos economicista e que busca privilegiar o discurso da inclusão social e da ação combinada e harmoniosa entre Estado, mercado e sociedade civil.

No caso das competências socioemocionais, concordância, consenso e disseminação de ideias associadas a essa noção devem ser atribuídos, em grande parte, à atuação que OCDE vem tendo junto aos países membros e associados, justificada pela suposta necessidade de compartilhamento de métodos de gestão e de políticas de 
DOI: $10.12957 / \mathrm{e}-\mathrm{mosaicos} .2021 .46754$

desenvolvimento econômico e social, tendo em vista a crescente globalização e interrelação das economias.

Rodrigues (2015), analisando os documentos que tratam das competências socioemocionais, observa que, apesar do discurso em que afirma atuar apenas em resposta aos anseios dos governos, a OCDE, exercendo o que autor chama de um "poder leve" (JAKOBI e MARTENS, 2010), estaria pondo em prática um verdadeiro projeto de governança educacional global. Esse projeto estaria assentado em três mecanismos de governança apontados por Jakobi e Martens (2010) - a produção de ideias, a avaliação de políticas e a geração de dados, e ainda, nos modos de governança cognitivo (agenda cooperativa e circulação de ideias) e normativo (compartilhamento de um conjunto e valores), descritos por Woodward (2009). Seguindo essa linha, Evangelista e Shiroma (2006) lembram que, no campo educativo, as diretrizes globalizantes emanadas pelos organismos internacionais atuam pela via da regulação e imposição na ação do Estado.

Como parte de uma agenda global para a educação, o desenvolvimento de competências socioemocionais pela escola tem sido legitimado pela argumentação persuasiva exercida por especialistas que prestam assessoria à $O C D E$, com destaque para economistas renomados como James Heckman. No Brasil, o IAS vem exercendo esse papel junto a governos estaduais e a órgãos da educação vinculados direta ou indiretamente ao MEC, reforçando ideias e implementando ações alinhadas a pauta dos novos "intelectuais coletivos" do capital (FRIGOTTO, 2005), como a OCDE.

Há de se questionar as dimensões epistemológicas e pedagógicas que sustentam tais concepções, bem como a superestimação da sua suposta cientificidade que escanteia o debate acadêmico e pedagógico acumulado por pesquisadores e professores comprometidos com a escola pública brasileira.

Smolka et al. (2015) questionam o suposto consenso sobre constructo teórico dos Big Five, referência utilizada pelo IAS e pela OCDE para orientar a construção de currículos e avaliação de competências socioemocionais. Dentre as abordagens sobre a personalidade que surgem e se desenvolvem na convergência entre a psicanálise e o materialismo histórico, os autores contrapõem ao constructo teórico dos Big Five, que se inspira na teoria lexical, as formulações de Eric Fromm, Henri Wallon representantes da perspectiva histórico-cultural (Vigotski, Leontiev e Luria) além de outras elaborações teóricas como a Positioning Theory, oriunda do pragmatismo norte-americano e do Interacionismo simbólico. Críticas de diferentes ordens ao modelo dos Big Five também são registradas por autores do campo da psicologia e referem-se ao uso da abordagem fatorial, ao seu caráter estático, determinista e empiricista que desconsidera a complexidade envolta nos múltiplos determinantes genéticos e ambientais e que constam da interação na formação da personalidade. Concluem as autoras que, diferente do que fora aventado, o modelo dos Big Five estaria longe de ser consensual ou inovador. 
DOI: $10.12957 / \mathrm{e}-\mathrm{mosaicos} .2021 .46754$

A Associação Nacional de Pós-Graduação e Pesquisa em Educação (Anped) emitiu nota em 06 de novembro de 2014, repudiando a avaliação em larga escola de competências socioemocionais. Situando o campo da economia como balizador da proposição dos testes, a Anped demonstra preocupação com o potencial desse tipo de avaliação na conformação do currículo, rotulação, estigmatização e culpabilização de crianças e jovens pelo fracasso escolar. O reducionismo que avaliações como estas podem redundar traria sérios impactos na formulação das políticas públicas.

Em junho de 2015, foi a vez do Centro de Estudos Educação e Sociedade (CEDES) manifestar-se contrariamente à mensuração de competências socioemocionais realizada pelo Instituto Ayrton Senna. A moção aprovada no V Seminário de Educação Brasileira (SEB) foi publicada em editorial do número 31 da Revista Educação e Sociedade. Dentre as razões que ensejaram a moção, destacam-se a concepção naturalizante da personalidade humana ancorada na psicologia dos traços, já amplamente criticada; a separação entre os aspectos cognitivos e socioemocionais - o que contrariaria os avanços produzidos por áreas dos conhecimentos como a psicologia, a pedagogia, a neurologia e as ciências sociais; a padronização característica do pensamento psicométrico que ignora a diversidade e as condições de desigualdade social abrindo margem para patologização e para estigmatização da diferença e finalmente a falta de consenso sobre o impacto da medição das competências socioemocionais no processo de ensino-aprendizagem.

Endossamos as críticas apontadas pela Anped e pelo CEDES e os questionamentos levantados por Smolka et al. A escola e os educadores que nela atuam sempre tiveram um papel fundamental na formação pessoal, afetiva e cognitiva dos educandos, mas se estrutura, de fato, como instância responsável pela formação cultural dos sujeitos, contribuindo para ampliação do acesso ao conhecimento historicamente produzido pela sociedade. Não sendo um mundo à parte, essa formação perpassa a dimensão da sociabilidade e das emoções já que comporta a relação professor-aluno como elemento pedagógico fundamental, sem o qual o processo propriamente educativo não se realiza. Entretanto, essa condição não deve subordinar o processo pedagógico a uma suposta necessidade de conformação psicossocial dos sujeitos, tomando aquelas dimensões como específicas ou exclusivas atribuições da escola. A escola participa da formação de competências socioemocionais dos alunos como consequência daquilo que the é próprio e segundo princípios axiológicos, éticos e políticos, construídos com base em concepções das quais os educadores participam direta ou indiretamente.

Para além disso, é importante olhar criticamente para a forma como os novos modos de gestão e de organização do trabalho e as mudanças operadas na base técnica do trabalho no regime de acumulação flexível colocam demandas para a formação de trabalhadores com vistas à constituição de arranjos flexíveis de competências diferenciadas (KUENZER, 2007). Operando, dessa forma, as competências socioemocionais caminham no sentido da revitalização da noção de competência cuja 
DOI: $10.12957 / \mathrm{e}-\mathrm{mosaicos} .2021 .46754$

lógica "incorpora alguns traços principais da Teoria do Capital Humano, mas os redimensiona com base na especificidade das relações sociais contemporâneas." (RAMOS, 2001, p.292)

\section{CONSIDERAÇõES FINAIS}

Ao longo deste artigo, procuramos reconstruir o percurso por meio do qual a noção de competências socioemocionais incorporou-se ao discurso e às propostas curriculares em diferentes níveis do sistema educacional brasileiro. Na educação básica, essa noção adquire materialidade no elenco de competências gerais descritas na BNCC. Com a reforma do ensino médio, sua transposição para o currículo é facilitada pela diversificação do percurso formativo, pela flexibilização das formas de integralização curricular e pela possibilidade de inclusão de componentes como projeto de vida e similares, tal como observamos na proposta do IAS implementada na rede estadual de ensino do Rio de Janeiro.

A emergência da noção de competências socioemocionais nas políticas públicas e o seu despontar nos discursos e nas ações práticas levadas a cabo por agentes públicos e privados parecem indicar um esforço e uma busca pela revitalização da noção de competências no campo da educação. A apologia em torno das competências socioemocionais apela para o conteúdo persuasivo de expressões como "inovação curricular", "evidência científica", "educação plena", "educação do século 21" na busca por consenso e por consentimentos que acolham a abordagem por competências na escola como panaceia para todos os males educacionais. Resta saber de que forma pretende-se operacionalizá-las no currículo e a partir de que referências epistemológicas, políticas e pedagógicas.

O progressivo refinamento e relativa autonomia que as competências socioemocionais adquirem neste momento se colocam a serviço do revigoramento de noções associadas à teoria do capital humano e do reforço de uma concepção de sociedade meritocrática, individualista e individualizante. Importa menos a coerência teórica em relação ao constructo das competências do que a convergência ideológica que unifica intenções político-pedagógicas de agentes do estado e do mercado.

Da sua incorporação na agenda educacional à implementação de políticas curriculares, a noção de competências socioemocionais evolui discursivamente de elemento que incrementa o desenvolvimento de competências cognitivas para ferramenta importante que governos devem considerar para diminuir as lacunas entre resultados educacionais, econômicos e sociais. (OCDE, 2014). Diferenças na forma de abordagem científica e na terminologia adotada em textos oficiais não refletem divergências de fundo. Pelo contrário, seja qual for o contexto discursivo ou normativo no qual as competências 
DOI: $10.12957 / \mathrm{e}-m o s a i c o s .2021 .46754$

socioemocionais têm se manifestado, a resiliência, a disciplina, o esforço, a perseverança, a estabilidade emocional e a capacidade de suportar pressões são aspectos, comportamentos e traços da subjetividade humanos mais ressaltados como fatores explicativos do êxito escolar, social e econômico de sujeitos individuais e coletivos.

Contudo, a adesão à pauta de temas como a incorporação das competências socioemocionais em políticas de currículo e avaliação não pode ser tratada como uma simples imposição por organizações internacionais e suas correias de transmissão. 0 cumprimento dessa agenda internacional conta com o consentimento explícito do Estado Brasileiro que, pressionado pela universalização da educação básica e pela exigência de padrões mínimos de qualidade, deliberadamente assume a defesa de propostas "inovadoras" e de concepções político-pedagógicas elaboradas em nível transnacional como panaceia para os problemas educacionais dos sistemas de ensino.

O movimento que tentamos captar gesta-se e desenvolve-se a partir de agentes públicos e privados comprometidos com um projeto de sociedade na qual até mesmo a subjetividade humana deve estar a serviço dos interesses econômicos. Cabe-nos o esforço de desvelar e de denunciar suas intenções e mais do que isso, apresentar e defender, como contraponto, perspectivas de educação e sociedade mais humanizantes, revolucionárias e emancipatórias que apontem para o desenvolvimento de uma sociedade que não aprisione a complexidade humana em categorias capturáveis e manipuláveis pelo capital.

\section{REFERÊNCIAS}

ANPED. Carta da ANPED sobre avaliação de habilidades socioemocionais. 06 de novembro de 2014. Rio de Janeiro. Disponível em

http://www.anped.org.br/sites/default/files/resources/carta_aberta_avaliac_a_o_habilidades_n a_o_cognitivas.pdf. Acesso em: 02/03/2021.

BRASIL.CNE/CEB. Parecer n 15/1998. Diretrizes Curriculares Nacionais para o Ensino Médio.

BRASIL.CNE/CEB. Parecer n 16/1999. Diretrizes Curriculares Nacionais para a Educação Profissional.

BRASIL. CNE/CEB Resolução nº 6/ 2012, que define Diretrizes Curriculares Nacionais para a Educação Profissional Técnica de Nível Médio. Brasília, 2012.

BRASIL. CNE/CEB. Resolução no 3/2018. Diretrizes Curriculares Nacionais para a Educação Profissional Técnica de Nível Médio. Brasília, 2018. 
DOI: $10.12957 / \mathrm{e}-\mathrm{mosaicos} .2021 .46754$

BRASIL. MEC. Base Nacional Comum Curricular. Documento Base. Brasília. 2018. Disponível em

http://basenacionalcomum.mec.gov.br/wp-content/uploads/2018/06/BNCC_EnsinoMedio_emb aixa_site_110518.pdf Acesso em: 18/09/2019.

BRASIL. Lei de Diretrizes e Bases da Educação. Brasília. 2018. Disponível em http://www.planalto.gov.br/ccivil_03/leis/19394.htm. Acesso em 10/11/2019.

CEDES E V SEB. CEDES E V SEB em tempos de pátria educadora. Editorial. Educação e Sociedade., Campinas, v. 36, no. 131, p. 287-295, abr.-jun., 2015.

CHAVES, David; DA MOTTA, Vânia Cardoso; GAWRYSZEWSKI, Bruno. Programa Solução Educacional: uma formação para a resiliência em tempos de agudas contradições. Perspectiva, 2020, 38.3: 1-21.

EVANGELISTA, Olinda; SHIROMA, Eneida Oto. Educação para o alívio da pobreza: novo tópico na agenda global. Quaestio-Revista de Estudos em Educação, v. 7, n. 2, p. 96-111, 2005.

FRIGOTTO, Gaudêncio. Concepções e mudanças no mundo do trabalho e o ensino médio. In:FRIGOTTO, Gaudêncio; CIAVATTA, Maria; RAMOS, Marise (Orgs.). Ensino médio integrado: concepções e contradições. São Paulo: Cortez, 2005.

KUENZER, Acácia Z. Da dualidade assumida à dualidade negada: o discurso da flexibilização justifica a inclusão excludente. Educação \& Sociedade, v. 28, n. 100, 2007

KUENZER, Acacia Z. Conhecimento e competências no trabalho e na escola. Boletim técnico do SENAC, v. 28, n. 2, p. 2-11, 2002.

KUENZER, Acacia Z. As relações entre conhecimento tácito e conhecimento científico a partir da base microeletrônica: primeiras aproximações. Educar em revista, n. SPE_, p. 43-69, 2003.

INSTITUTO AYRTON SENNA. Uma visão mais ampla sobre a qualidade do aprendizado. Seminário Educação para o Século 21. Disponível em http://www.educacaosec21.org.br/seminario2011/seminario/ . Acesso em: 10/11/2019.

. Solução Educacional para o Ensino Médio. Volume 1: Conceitos. Rio de Janeiro. 2012.

OCDE. Fórum Internacional de Políticas Públicas "Educar para as Competências do Século 21". São Paulo. 2014. Disponível em: http://www.educacaosec21.org.br/foruminternacional2014/. Acesso em: 10/11/2019. 
DOI: $10.12957 / \mathrm{e}-\mathrm{mosaicos} .2021 .46754$

. The definition and Selection Of Key Competencies. Executive Summary. 2005. Disponível em https://www.oecd.org/pisa/35070367.pdf Acesso em 10/11/2019.

. Estudos da OCDE sobre competências: competências para o progresso social: o poder das competências socioemocionais. Tradução de Maria Carbajal. São Paulo: Fundação Santillana, 2015.

LEHER, Roberto. EVANGELISTA, Olinda. Todos pela educação e o episódio Costin no MEC: a pedagogia do capital em ação na política educacional brasileira. Revista Trabalho Necessário. Ano 10, número 15. 2012.

MACHADO, Lucília Regina de S. O" Modelo de Competências" e a regulamentação da Base Curricular Nacional e de Organização do Ensino Médio. Trabalho \& Educação, v. 4, p. 79-95, 1998.

RAMOS, Marise Nogueira. A pedagogia das competências: autonomia ou adaptação? São Paulo: Cortez, 2001.

RAMOS, Marise N.. A educação profissional pela pedagogia das competências e a superfície dos documentos oficiais. Educação e sociedade, v. 23, n. 80, p. 401-422, 2002.

RODRIGUES. Carlos Eduardo Serrina de Lima. Habilidades socioemocionais: a OCDE e seu projeto de governança educacional global. 37a reunião nacional da Anped - 04 a 08 de outubro de 2015, UFSC- Florianópolis.

SEEDUC/RJ. Solução Educacional para o Ensino Médio. Notícias. 06/01/2015. Disponível em http://www.rj.gov.br/web/seeduc/exibeconteudo?article-id=2299715. Acesso em 18/11/2016.

Resolução 4842/2014. Fixa diretrizes para implantação das matrizes curriculares para educação básica nas unidades escolares de ensino médio integrado à educação profissional e ensino médio experimental. Diário Oficial do Estado do Rio de Janeiro. 06/12/2012.

. Resolução 4843/2012. Fixa diretrizes para implantação das matrizes curriculares para a educação básica nas unidades escolares da rede pública e dá outras providências. Diário Oficial do Estado do Rio de Janeiro. 06/12/2012.

SMOLKA, Ana Luiza Bustamante et al. O problema da avaliação das habilidades socioemocionais como política pública: explicitando controvérsias e argumentos. Educação \& Sociedade, v. 36, n. 130, 2015. 
DOI: $10.12957 / \mathrm{e}-\mathrm{mosaicos} .2021 .46754$

VIERA, André H. P. Competências socioemocionais e desempenho educacional no Brasil: uma análise de equações estruturais e pareamento com os dados do PISA 2012. Dissertação de Mestrado. Universidade Federal de Minas Gerais. Belo Horizonte. 2015.

Recebido em 17 de novembro de 2019

Aceito em 04 de abril de 2021

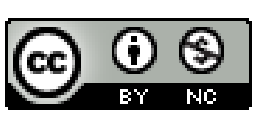

A e-Mosaicos Revista Multidisciplinar de Ensino, Pesquisa, Extensão e Cultura do Instituto de Aplicação Fernando Rodrigues da Silveira (CAp-UERJ) está disponibilizada sob uma Licença Creative Commons - Atribuição - NãoComercial 4.0 Internacional.

Os direitos autorais de todos os trabalhos publicados na revista pertencem ao(s) seu(s) autor(es) e coautor(es), com o direito de primeira publicação cedido à e-Mosaicos.

Os artigos publicados são de acesso público, de uso gratuito, com atribuição de autoria obrigatória, para aplicações de finalidade educacional e não-comercial, de acordo com o modelo de licenciamento Creative Commons adotado pela revista. 